\title{
Recetario en busca de dueño: perfumería, medicina y confitería en la casa del VII Duque de Montalto (1635-1666)
}

\author{
Laura Oliván SANTALIESTRA \\ Universidad de Granada \\ lauraolivan@yahoo.es \\ Rafaella PILO \\ Universidad de Sassari \\ rafaella@hotmail.it
}

Recibido: 10 de mayo de 2010

Aceptado: 24 de febrero de 2011

\section{RESUMEN}

El documento número treinta de la sección de manuscritos del conde de Harrach, conservado en el Archivo de Estado de Viena, es un recetario doméstico de notable interés en el que un desconocido personaje -cuya identidad se revela en este artículo- realizó numerosas anotaciones personales. Estas clarividentes notas desvelan los usos y prácticas del perfume en una casa nobiliaria del siglo XVII. Aguas de olor, pebetes, pastillas y pomas son algunos de los productos que se podían elaborar siguiendo las instrucciones de las recetas. Un detenido análisis del manuscrito nos ha permitido descubrir al dueño y autor de las anotaciones, además de profundizar en el significado del perfume para las élites nobiliarias de la monarquía hispánica.

Palabras clave: Perfume, siglo XVII, médico, corte, VII duque de Montalto, Catalina de Moncada.

\section{A recipe Book in Search of an Owner: Perfumery, Medicine and Confections in the House of the Seventh Duke of Montalto (1635-1666)}

\begin{abstract}
.
Document number thirty from the manuscripts of the Count of Harrach, preserved in the Vienna State Archives, is an exceptionally interesting home recipe book that contains numerous personal annotations by a person whose identity we will reveal in this article. These insightful notes reveal details regarding the practices and use of perfume in a home of the nobility in the 17th century. Perfume waters, incense, pastilles and pomanders are some of the products that could be prepared by following the instructions in the recipes. A detailed analysis of the manuscript has led us to discover the owner and author of the annotations, as well as get a better understanding of the significance of perfume for the noble elite of the Spanish monarchy.
\end{abstract}

Key words: Perfume, $17^{\text {th }}$ century, doctor, court, VII duque of Montalto, Catalina of Moncada. 


\section{UN RECETARIO DE LA CASA DE MONTALTO EN EL ARCHIVO HARRACH DE VIENA}

Una mañana del mes de abril de 2007, mientras buscaba documentación sobre la reina doña Mariana de Austria y su relación con la familia del conde de Harrach en el Österreichisches Staatsarchiv de la ciudad de Viena, encontré un curioso manuscrito encuadernado que contenía numerosas recetas escritas en castellano. Pebetes, pastillas de olor y aguas perfumadas se intercalaban con alcorzas, bolsitas de olor y alguna confitura. El perfume y la confitería predominaban en aquel prontuario doméstico destinado a cubrir de delicias, olores y sabores a una refinada familia aristocrática profundamente vinculada a la monarquía hispánica: La Casa de Montalto. Una copia parcial de este manuscrito se encuentra en el Archivo Histórico Nacional ${ }^{1}$. La principal diferencia que presenta con el de Viena, sin contar que el número de recetas del manuscrito vienés es mayor, es que a pesar de que permanecen las indicaciones de los personajes que le suministraron las preciadas fórmulas y su procedencia, no hay rastro de las valiosas anotaciones de los márgenes que sí aparecen en el recetario de Viena y que tienen la virtud de aportar las claves para descubrir al practicante y recopilador de las recetas, sin duda perteneciente al servicio de don Luigi Guglielmo de Moncada Aragón, VII duque de Montalto y futuro cardenal Moncada ${ }^{2}$.

El recetario encuadernado de Viena figura en el catálogo del Österreichisches Staatsarchiv como el número 30 de los Harrach Handschriften ${ }^{3}$. Es probable que uno de los condes de Harrach que fueron embajadores en España -seguramente Fernando de Harrach- lo comprara, lo adquiriera en almoneda o lo recibiera como regalo en pago a sus denodados esfuerzos al frente de la difícil embajada imperial en el Madrid del último tercio del XVII. Incluso no sería descabellado pensar que el mismo Fernando de Harrach lo hubiera ordenado copiar para ofrecérselo a su esposa, Johanna Theresia Lamberg, antigua dama de la reina doña Mariana de Austria. La condesa de Harrach era conocida en la ciudad imperial como la suprema embajadora cultural de la corte de Madrid. Famosa escritora de Tagzettel ${ }^{4}$ estudiados por Susanne Claudine Pils ${ }^{5}$, Johanna Teresia solicitó en más de una

Agradezco a Fernando Bouza el haberme facilitado la referencia de este manuscrito. AHN, diversos, colecciones, leg 336. BouzA, F: "Culturas de élite, cultura de élites. Intencionalidad y estrategias culturales en la lucha política de la aristocracia moderna", en Soria Mesa, E.; Bravo Caro, J. J. y Delgado Barredo, J. M. (eds): Las élites en la época moderna: La Monarquía Española, vol I. Nuevas perspectivas, Córdoba, Universidad de Córdoba, 2009. p. 40.

2 Pilo, R.: "Moncada-Aragón y La Cerda Luís Guillermo", en Diccionario Biográfico Español, Madrid, Real Academia de la Historia, en prensa.

3 Österreichisches Staatsarchiv-Allgemeines Verwaltungarchiv, Familien Archiv (ÖSTA-AVA. FA) Harrach Handschriften. № 30. Sammlung verschiedener Rezepte in Spanischer Sprache.

4 Fuente especial, según Bianca Lindorfer, «entre carta y diario», véase LINDORFER, B.M: "Las redes familiares de la aristocracia austriaca y los procesos de transferencia cultural: entre Madrid y Viena, 1550-1700", en Yun CASALILLA, B. (coord.): Elites sociales en la articulación de la monarquía hispánica (1492-1714), Madrid, Marcial Pons, 2009, pp. 261-288.

5 PILs, S. Cl: Schreiben über Stadt. Das Wien der Johanna Theresia Harrach 1639-1716, Wien, Franz Deutiche, 2002. PILS, S.CL: "Schreiben aus der Stadt. Die Tagzettel der Johanna Theresia Gräfin Harrach an ihren Mann Ferdinand Bonaventura Graf Harrach 1665 und 1676/77”, en HACKE, D. (ed): 
ocasión a su esposo, recetas españolas para elaborarlas en Viena y así presumir ante su círculo social de sus renovados secretos culinarios, de "prestigioso" origen hispano. Bianca Lindorfer ha analizado el interés de esta condesa por este tipo de recetas españolas: Johanna adoraba el chocolate, que había degustado en su juventud en casa de Francisca Manrique ${ }^{6}$, y los tomates, que introdujo de manera pionera en la ciudad imperial con semillas procedentes de España ${ }^{7}$. El gusto y cultura de la condesa nos hace sospechar que podría haber sido suya la iniciativa de encargar aquellas recetas. Con casi total seguridad, este recetario escrito en castellano, lengua que la condesa dominaba, llegó a sus manos a través de su marido o de los contactos sociales que hizo en Madrid ${ }^{8}$.

\section{SORPRENDENTE DUEÑO DEL RECETARIO DOMÉSTICO}

A primera vista, el recetario hallado en Viena presenta todas las características que la historiografía atribuye a los prontuarios domésticos españoles de la Edad Moderna: Manuscritos encuadernados generalmente anónimos, cuya posesión suele atribuirse a mujeres de alta condición que suscriben, antes o después de las fórmulas anotadas, la dama reveladora del secreto: «Receta que ensenyó la marquesa de Villena para las pastas $»^{9} \mathrm{O}$ 《las pastillas que haze la condesa de puñoenrostro» ${ }^{10}$; todas ellas mujeres de alta alcurnia, primas, hermanas, tías, abuelas o amigas íntimas que se transmitían sus más preciadas fórmulas, verdaderos secretos de familia en forma de recetas médicas, higiénicas, cosméticas, aromáticas o culinarias. Los resultados servían para demostrar su alto grado de refinamiento en los círculos cortesanos.

La aparente heterogeneidad de los usos de las recetas, desde las alcorzas, (pequeños dulces) hasta las cremas para el rostro o los remedios para el dolor de cabeza, se diluye al reflexionar sobre el origen culto de estos recetarios, dignos herederos tanto de las cosmológicas concepciones médicas de Hipócrates y Galeno, en las que la solución al desequilibrio fisiológico se encuentra en un tratamiento holístico; como de la dietética propia de los regimina sanitatis de la Edad Media, obras de reputados médicos destinadas a los magnates de los siglos XIII y XIV, en las que se intentaba, según Alicia Martínez Crespo, establecer un régimen de vida apropiado para un noble determinado, basándose en el estudio personalizado de sus condiciones fisiológicas que se entendían como especiales por su naturaleza superior ${ }^{11}$. Por

Selbestzeugnisse frühneuzeitlicher Städterinnen. Heildelberg, Tagungsband, en prensa. PILS, S.: "Die Tagzettel der Gräfin Johanna Theresia von Harrach als Sonderform des Briefes", en Pauser, J.; Scheutz, M. y Winkelbauer, Th. (eds.): Quellenkunde der Habsburgermonarchie in der Frühen Neuzeit. Ein exemplarisches Handbuch, Viena, 2004, pp. 790-795.

6 LindoRfER: $o p$, cit, (nota 4) p. 280.

7 Ibidem, p. 279.

8 Ibidem, p. 280.

9 Biblioteca Nacional de España (BNE), Manuscritos (Mss), 2019.

10 BNE, mss, 1462.

11 Martínez CRespo, A (ed): Manual de mugeres en el qual se contienen muchas y diversas reçetas muy buenas, Salamanca, ediciones Universidad de Salamanca, 1995. p. 13. 
tanto, la dieta que debía seguir el noble tratado, debía ser diferenciada y seguir la jerarquía de alimentos, esencias y plantas medicinales más adecuadas a su egregia condición.

Las recetas imbuidas de galenismo o de los preceptos de Dioscórides podían servir para dos o más usos de los que en principio parecen destinadas, de modo que una confitura o unas alcorzas que podrían concebirse como dulces aristocráticos destinados a satisfacer al sentido del gusto, servirían igualmente para sanar el cuerpo, ya que el azúcar era altamente considerado por la nobleza debido a sus propiedades curativas ${ }^{12}$. Y es de esta manera cómo un perfume podía servir a la medicina o para embellecer cuerpos y almas de los nobles. Es evidente que en estos recetarios, resulta difícil deslindar la medicina de la cocina (en concreto de la confitería ${ }^{13}$ ), la cosmética de la higiene, o el arte de elaborar perfumes de la fineça, cada vez más demandada por las élites nobiliarias.

Los recetarios, como se ha apuntado, suelen ser anónimos, se presentan sin firma o a lo sumo aparece una breve rúbrica que representa de manera algo fútil, a la persona poseedora de aquellas recetas, posiblemente la misma que experimentó -si no por sí misma- por aquellos que estuvieron a su servicio. Sin duda el anonimato y el hecho de que sean cuadernos manuscritos en tiempos en los que la imprenta protagonizaba su gran papel difusor, revelan la vocación de "secreto" que tenía este tipo de documentación. Sin lugar a dudas, las recetas eran consideradas por sus poseedores como privilegiados tesoros. En gran medida, este carácter secretista respondía a su carácter múltiple y a las infinitas variaciones de las mismas, a pesar de que los ingredientes podían reducirse a un reducido número: La fórmula mágica, la combinación perfecta de simples y técnicas que convertían a la receta en exitosa, sólo podía obtenerse tras años de experimentación.

María de los Ángeles Pérez Samper, en su artículo "Los recetarios de mujeres y para mujeres. Sobre la conservación y transmisión de los saberes domésticos en la época moderna" 14 ha estudiado brillantemente estos prontuarios domésticos españoles: El manual de mugeres en el cual se contienen muchas y diversas recetas muy buenas ${ }^{15}$ de 1475-1525, editado por Alicia Martínez Crespo con una buena introducción; y diversos libros de recetas que se conservan en la Biblioteca Nacional de Madrid: Libro de receptas de pivetes pastillas y conservas ${ }^{16}$; Recetas y memorias para guisados, confituras, olores, aguas, afeites, adobos de guantes, ungüentos y medicinas para muchas

12 Ibidem, p. 14. La misma autora cita en la nota 13 una obra significativa: Pérez VIDAL, J: Medicina y dulcería en el Libro del Buen amor, Madrid, Cupsa, 1981.

13 Serrano Lárraoz, F.: "Confitería y gastronomía ("libros" IV-VI) en El Regalo de la Vida Humana de Juan Vallés", en vallés, J.: Regalo de la Vida Humana. Estudios y transcripción, Gobierno de Navarra-Österreichische Nationalbibliothek, Pamplona, 2009. p. 205.

14 Pérez SAmper, M. A: "Los recetarios de mujeres y para mujeres. Sobre la conservación y transmisión de los saberes domésticos en la época moderna", en Cuadernos de Historia moderna. Sobre la mujer en el Antiguo Régimen: de la cocina a los tribunales. Monográfico III, número 19, Madrid, Universidad Complutense, (1997), pp. 121-154.

15 MARTíneZ CRESPO: op, cit, (nota 11), p. 27. El manuscrito editado por la autora se encuentra en la Biblioteca Palatina de Parma, Mss, Parmense 834.

16 Bne, mss, 1462. Perez Samper: op, cit, (nota 14), pp. 136-137. 
enfermedades ${ }^{17}$ y el manuscrito Receptas experimentadas para diversas $\operatorname{cosas}^{18}$. Otras obras manuscritas han sido analizadas con igual atención por Montserrat Cabré i Pairet en su estudio: "Los consejos para hermosear el cuerpo ("libros" I-III) en El Regalo de la Vida Humana de Juan Vallés", donde la autora y especialista en cosmética medieval cita: El Vergel de señores en el qual se muestran a hazer con mucha exçelencia todas las conservas, electuarios, confituras, turrones y otras cosas de açúcar y mie ${ }^{19} l$. Todos estos manuales presentan la tipología propia antes apuntada: Anonimato y huella o mano mujeril -no tan clara en el Vergel- en autoría, pertenencia y elaboración. De ahí que estos recetarios se hayan calificado de «femeninos», obras de mujeres destinadas a mujeres ${ }^{20}$.

Con esta razonable y lógica tradición historiográfica que establecía la ecuación: mujer noble-recetario doméstico, pensé que el manuscrito de Viena se trataba del manual de alguna dama, eso sí, apasionada de los perfumes y conocedora de las más exquisitas técnicas de destilación. Con el fin de descubrir la identidad de la "presunta dueña", me dispuse a leer atentamente las anotaciones experimentales realizadas al margen de las recetas: A veces señalaba que la fórmula era muy buena o al contrario, que no le gustaba o que suponía gastar sin buenos resultados; otras se atrevía a sugerir variaciones: Añadir o quitar ingredientes, destilar de otra manera, utilizar otros recipientes; completaba sus breves notas con una referencia de gran valor porque, quizás con un interés recordatorio, anotaba el año y la ciudad donde había conseguido la receta y la persona que se la había proporcionado. La atenta lectura de todas las notas personales de este curioso manuscrito enterrado entre los miles de documentos pertenecientes a la familia Harrach de Viena, me permitió descubrir que la "dueña" de tan preciado libro de secretos y "autora" del centenar de notas explicativas de las bondades o inutilidades de cada una de las recetas no era una mujer sino un hombre. Un dato fue revelador para desempolvar la identidad masculina del perfumista: en dos ocasiones tildaba de supersticiones de mujeres algunas de las técnicas utilizadas en la elaboración de las aguas perfumadas: «en superstición de Mugeres basta que esten machacados y ponerlos en enfusion sin lavarlos $\rangle^{21}$, suscribía al comentar la receta de... y al juzgar una receta de la princesa de Pacheco, no dudaba en sentenciar «a mi me parece un disparate ni veo que tenga que hacer con el calambuco que es cosa natural estos son embustes de mujeres... $\rangle^{22}$, eso sí, a nuestro entender, de mujeres de altos linajes, a las que sí se les permitía (junto a las monjas ilustres de los monasterios reales) practicar estas recetas aromático-medicinales que realizadas por mujeres de baja condición podrían haber sido calificadas como actos de magia ${ }^{23}$ o brujería, o como «supersticiones» de las que se hacía eco el dueño del recetario.

17 BNE, mss, 6058, Ibidem, pp. 137-138.

18 BNe, mss, 2019, Ibidem, p. 139.

19 CABré i Pairet. M.: "Los consejos para hermosear el cuerpo ("libros” I-III) en El Regalo de la Vida Humana de Juan Vallés", en VALLÉs: op, cit, (nota 13) pp. 173-202.

20 PÉREZ SAMPER: op, cit, (nota 14), p. 121.

21 ÖSTA-AVA.FA. Harrach Handschriften. №30. p. 2v.

22 Ibidem, p. 24.

23 María Helena Sánchez Ortega cita casos de mujeres no privilegiadas que practicaban la magia amorosa con preparados similares a los presentados por los recetarios domésticos: «María Rodera [Toledo, siglo XVII] preparaba pucheros en los que mezclaba ruda, piedra alumbre y «alquiribite» 
Desechada la hipótesis de que pudiera pertenecer a una dama noble, centré mis investigaciones en las fechas, las ciudades y la identidades de las personalidades suministradoras de recetas, de esta manera pude descubrir que el personaje era sirviente de los duques de Montalto a los que se refiere con gran deferencia: «mi señora la duquesa de Montalto», o «mi dueño y señor, el duque de Montalto», al que también califica de «mi amo». Las anotaciones destapan toda la red familiar y clientelar del VII duque de Montalto a la que pertenecen la mayor parte de las recetas, incluso hay una suscrita por el mismo duque: una memoria para perfumar aguas una «nota [que] estava entre las recetas de mi suegro el duque de alcala mi señor $\rangle^{24}$, frase que sólo puede ser de este noble que se presenta cual apasionado de los perfumes y aromas «fuertes» ${ }^{25}$, en palabras del dueño del recetario.

¿Quién es este misterioso personaje, criado del VII duque de Montalto y su esposa doña Catalina Moncada? Lo descubrí al leer un artículo que la doctora Rafaella Pilo, muy amablemente, me envió para que conociera sus investigaciones sobre doña Catalina de Moncada. Este trabajo que permanece en prensa desde el año $2006^{26}$ citaba a esta misteriosa personalidad: sus viajes, sus amos y su oficio. Con la premura que suscita la emoción de un nuevo descubrimiento, avisé a Rafaella Pilo de mi hallazgo y le pedí que como especialista en el personaje me confirmara mi intuición. Y así lo hizo: estaba en lo cierto, el manuscrito contenía las recetas que una vez pertenecieron, sin dudas, a Gavino Farina ${ }^{27}$, médico del VII duque de Montalto que alcanzó el título de médico de cámara de Mariana de Austria y Carlos II. Los detalles de sus venturas y desventuras los dará Pilo al final del artículo.

La atribución de las anotaciones de los márgenes a un médico de renombre como Farina permite abrir muchos interrogantes sobre los recetarios domésticos y su relación con las altas esferas de la medicina, consideradas tradicionalmente, si no como detractoras, receladoras de los prontuarios domésticos y ello a pesar de que presentaban una fuerte impronta de los antiguos tratados de la medicina clásica. Tras descubrir la identidad del poseedor del manuscrito, un médico, podemos afirmar que las altas personalidades en el arte de la medicina ${ }^{28}$ no vivieron ajenas a los recetarios domésticos de los siglos XVI y XVII que la historiografía ha asociado casi en exclusiva al mundo femenino.

en vinagre fuerte, lo cocía para que después se pudiera rociar con ese mejunje la puerta del galán desdeñoso» SÁnchez Ortega, M. H: Ese viejo diablo llamado amor. La magia amorosa en la España Moderna, Madrid, UNED, 2004, p. 339.

24 Östa-Ava.Fa. Harrach Handschriften. No 30. p. 43.

25 Ibidem, p. 2.

26 Pilo, R: "El médico sardo Gavino Farina: Un científico galénico en la corte del rey de España", Fundación Española de Historia Moderna, en prensa. Agradezco a la autora el haberme proporcionado este artículo antes de su publicación. Su lectura me permitió descubrir al dueño del recetario e iniciar una colaboración científica con la autora. Añado otra publicación suya: PILO, R: "Il medico sassaresse Gavino Farina: lo schizzo biografico di uno scienziato galenico alla corte del Re di Spagna", en Atti del $3^{\circ}$ congresso in Sardegna di Storia della Medicina, Cagliari, 7-8 octubre, Sole, Cagliari, pp. 203-214.

27 PILo, R: "Farina Gavino", en Diccionario Biográfico Español, Madrid, Real Academia de la Historia, en prensa.

28 Daynes-Diallo, S: Ars Medicina. Médicine et savoir au XVI siècle, París, Museo Nacional del Renacimiento, 2008. 
Un hombre y además médico custodiaba el recetario y parece que no fue la excepción, pues algunas de las recetas apuntadas por Farina provenían de hombres, duques, guanteros, médicos, obispos, frailes o incluso de personajes masculinos de los que no se indica oficio ni condición, simplemente nombres y apellidos que los sitúan en el carnaval de los plebeyos; y aunque sería una locura desechar que fueran las mujeres las más aficionadas a este tipo de recetarios, a la luz de este descubrimiento, creemos que se debería reformular el entramado social que hizo uso de este tipo de prontuarios, porque quizás no sólo guiaron la práctica de "secretos" en cocinas u otros espacios mujeriles como los monasterios de monjas $^{29}$, sino también en reductos privilegiados de magnates masculinos, lugares destinados únicamente para la elaboración de aguas medicinales y perfumes de lujo ${ }^{30}$, llenos de alquitaras y alambiques para destilar; en definitiva, verdaderos laboratorios caseros que pertenecerían no sólo a las mujeres de la familia a las que se valoraría socialmente por estos conocimientos, sino también a los médicos de la Casa, galenistas e hipocráticos, además de reputados científicos especializados en las materias simples.

\section{EL RECETARIO DE VIENA: DESDE LAS ALZORÇAS DE BARRO O CHOCOLATE HASTA LOS PERFUMES QUE SE BEBEN, SE VEN O SE TOCAN}

El recetario de Viena se compone de 111 recetas: 52 aguas perfumadas, dos aguas para beber, siete vinagres para rociar, 24 pastillas, dos almohadillas de olor, tres po$\operatorname{mos}^{31}$, un acerico, ocho polvos de olor, dos pebetes, una pasta de cuentas, siete alcorzas, una confitura y unos de guantes de almizcle. El perfume es el indiscutible triunfador; predomina y domina en todas y cada una de las fórmulas apuntadas en las hojas de recetario.

La elaboración de aguas de olor en Occidente durante la Edad Media y el Renacimiento fue una costumbre médico-higiénica propia de las clases privilegiadas, heredada del mundo árabe en técnicas, instrumental y filosofía. La destilación de las aguas tratadas aromáticamente mediante alambiques fue práctica habitual en los suntuosos palacios musulmanes y en la Castilla medieval, foco conector de culturas donde la fabricación de aguas perfumadas o pastas olorosas se popularizó como efectivo remedio contra las pestes. Los miasmas o malos aires de los que procede el término malaria (mal aire) se consideraron desde antiguo la causa fundamental de las enfermedades ${ }^{32}$, por lo que médicos y nobles utilizaron el perfume ambiental

29 Pérez SAMPer: op, cit, (nota 14), p. 124.

30 Algunas aguas como la de Córdoba, eran compradas por el duque de Montalto: ÖSTA-AVA. FA.

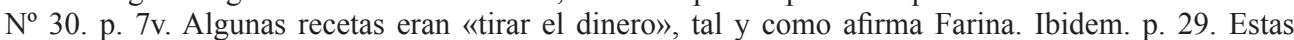
apreciaciones demuestran que los ingredientes se compraban a altos precios y los productos resultantes eran artículos de lujo que se regalaban, quizás con fines políticos.

31 Pastas de olor de forma redondeada que servían para rellenar las pomas, como más adelante se verá.

32 El aire, considerado como sexto elemento, fue objeto de un riguroso control, ya que se suponía que de su pureza y proporción, dependía la salud. Pounds, N.: La vida cotidiana: historia de la cultura material, Barcelona, Crítica, 1992, p. 286 
cual medida profiláctica para la prevención de enfermedades contagiosas. El médico de la peste, la célebre y algo estrambótica máscara veneciana de la Commedia dell' Arte que representa a un especialista en medicina cubierto de pies a cabeza con una máscara que simula un ave, fue un atuendo inventado por un médico francés llamado Charles de Lorme para visitar a los enfermos: el susodicho, al calor de la firme creencia de que el perfume podían combatir las plagas pestíferas, se cubría el rostro con un gran pico con la punta rellena de hierbas aromáticas, así pensó que podría librarse de la terrible epidemia ${ }^{33}$.

Dos técnicas fundamentales convivieron en la Edad Media y el Renacimiento para la elaboración de perfumes: la cocción y secado al sol durante horas de las mezclas aromáticas y la destilación. Ésta última técnica proveniente de Oriente, se difundió en occidente renacentista gracias a la imprenta. En 1500, el médico de Estrasburgo Jérôme Braunschweig publicó el primer tratado de destilación de perfumes, titulado: Liber de arte distillandi de simplicibus ${ }^{34}$, el hecho de que un médico se dedicara a explicar el método de destilación de simples es una prueba fehaciente de la estrecha relación existente entre el perfume y la medicina, y de su interés suscitado por la elaboración de tales preparados aromáticos.

En el siglo XVII se comenzaron a popularizar las aguas aromáticas como elemento de distinción social. En la Edad Media, la mayor parte de los perfumes eran fáciles de realizar porque las materias primas, llamadas simples por la ciencia médica, no eran caras. Pero poco a poco, la especialización en el mundo de la perfumería convirtió este arte mecánico en exclusivo. La dificultad que entrañaba el conseguir determinados ingredientes de lujo, algunos provenientes del extremo Oriente o las Indias ${ }^{35}$, hizo que el perfume profiláctico se convirtiera en un emblema del refinamiento. En el recetario de Farina hay muchos indicios que demuestran que los perfumes estaban al alcance de muy pocos y que en ocasiones, ingredientes y productos ya elaborados circulaban por el mercado exclusivamente nobiliario. Algunas aguas se compraban y se hacían llegar desde los lugares más conocidos por su elaboración: Como el recetario indica, el duque de Montalto hacía llegar la famosa agua de Córdova desde aquella ciudad, donde suponemos, era elaborada en los monasterios. Podría pensarse que durante el largo viaje las aguas perderían sus esencias y propiedades, pero tal y como se deduce del manuscrito muchas de las aguas perfumadas aguantaban muchos meses, quizás hasta un año si se cumplían a rajatabla las instrucciones o los ritos de conservación. Otros productos de olor tenían igualmente su denominación de origen, por ejemplo: el médico recomendaba los polvillos de Portugal: «polvillos ricos y si fueren de los de Portugal, mejor ${ }^{36}$ que suponemos compraba su amo o acaso, se los proporcionaba Leonor de Melo, dama portuguesa, esposa del marqués de Castelrodrigo, también de origen portugués que a su vez podría haberlos encargado a merca-

33 Eustace, P.: Venetian Mask and the Commedia dell'Arte, Verona, Arsenale, 2009, p. 14.

34 Bimbenet-Privat, M.: "Bijoux de senteur", Le bain et le miroir. Soins du corps et cosmétiques de l'Antiquité à la Renaissance, Paris, Gallimard, 2009. p. 322.

35 Los descubrimientos y el desarrollo de las comunicaciones en el siglo XVI enriquecieron las fórmulas aromáticas con nuevas sustancias muy buscadas por mercaderes y magnates. Ibidem, p. 322.

36 Östa-Ava. Fa. Harrach Handschriften. №30. Nota A. p. 1v. 
deres lusitanos, muy en contacto con las Indias. Las aguas perfumadas cual objetos exclusivos acabarían por transformarse en objetos sólidos susceptibles de ser vistos y tocados. Pero comencemos por las aguas que sirvieron principalmente al sentido del olfato.

El recetario de Farina incluye más de cincuenta aguas perfumadas realizadas mediante la mezcla de ingredientes aromáticos machacados, macerados al sol o destilados con alquitaras y demás instrumental. Los ingredientes son parecidos en todas las recetas de perfumes: algalia, almizcle, rosas, menjuí, estoraque, ámbar, azucenas, mosqueta, mirta, juncia, naranjas, azahar o trébol. Estas aguas tenían un fuerte carácter medicinal y servían para perfumar aposentos o rociar telas o estancias, un uso que no suele especificar el manuscrito ya que era evidente para el compilador de las recetas. En una nota a la «memoria de la cazoleta de monja», Farina suscribe: «olorcilo muy lindo para un aposentillo hacíamos cocer los pedaçitos de búcaro con agua de ambar de cordova de la mas rica $\rangle^{37}$. Las aguas se dejaban reposar en redomas en un rincón de la sala hasta que las esencias se evaporaban y era necesario recuperarlas; bella es la forma de renovar el perfume del agua de palas: «la echaran en redomas [el agua] y quando quieran que huelan los aposentos hara asqua una pala de yerro y echaran un poco de agua en ella la qual menearan bien en la Redoma quando la querran echar para que se mezcle el asiento con el agua ${ }^{38}$.

La juncia parece ser uno de los ingredientes estrella tal y como demuestran las siguientes recetas: «memoria para aderezar vinagre de juncia» ${ }^{39}$, «memoria de cómo se hace la juncia $\rangle^{40} \mathrm{o}\langle\text { (memoria de las juncias de las porcelanas }\rangle^{41}$, todas facilitadas por la marquesa de Castelrodrigo que debía ser una verdadera experta en el tratamiento de esta planta. Dos recetas de juncia para porcelanas llegaron a Farina a través de Antonio Cobos, su guantero, en Madrid el año de 1644, otra pertenecía a Catalina de Moncada y otra se la proporcionó Antonio de Casanueva, también en Madrid y el mismo año de 1644. El agua de juncia era ya muy apreciada en el Alcázar cuando Farina llegó a la corte de Felipe IV. Las notas de Cassiano del Pozzo, acompañante del cardenal Francesco Barberini en su viaje a Madrid, lo demuestran. Del Pozzo nos brinda un curioso testimonio del uso de agua de juncia en los aposentos del palacio real con motivo de un banquete destinado a agasajar al egregio cardenal, la cita es del 10 de junio de 1626 y en ella Cassiano asimila el buen olor a la salud:

«En estas estancias se vieron los fogones de plata adornados con flores [...] Se usó tambien un perfume de iuntia ${ }^{42}$, que es una raíz procedente de una espacie de junco o ciperácea de las que había en los alrededores de Madrid, que una vez lavada y puesta a secar, se prepara con cuidado y se coloca en recipientes de cristal, cubriéndose o impregnándose de vinagre al que, mientras está caliente, van añadiendo

37 Ibidem, p. 10v.

38 Ibidem, p. 14.

39 Ibidem, p. 8.

40 Ibidem, p. 9 v.

41 Ibidem, p. 10.

42 La editora del diario no ha identificado esta palabra que sin duda se refiere a la juncia. Véase receta de la juncia en el recetario de Farina: Ibidem. p. 10. 
claveles y algalia, quienes alguna cosa de olor, quienes otra cosa según gusto. Estas raíces, de esta manera conservadas y mantenidas [siempre] cubiertas por este vinagre elaborado, desprenden agradabilísimo y sanísimo olor» ${ }^{43}$.

La anotación que Cassiano hizo en su diario se asemeja a las recetas recogidas por Gavino Farina ¿Quién habría elaborado en aquel año de 1626 el agua de juncia que disfrutó el cardenal Barberini y su séquito papal? Al menos sabemos que veinte años después, dos guanteros y un desconocido Juan Francisco Andrés entendían de juncias en la corte de Madrid.

El mismo efecto que las aguas depositadas en redomas o porcelanas en los aposentos, tenían las pastillas y los pebetes, pastas perfumadas que exhalaban su perfume mediante combustión. El diccionario de la Real Academia de la lengua define pebete como: «Pasta hecha con polvos aromáticos, regularmente en forma de varilla, que encendida exhala un humo muy fragante». El recetario de Farina demuestra que estos preparados eran habituales: «las pastillas de brasa que hacen en Casa del duque de Montalto» ${ }^{44}$, «los pevetes negros y los pevetes blancos de la duquesa de Bivona ${ }^{45} \mathrm{y}$ «los pomos ricos para la lumbre» ${ }^{46}$. El uso de las pastillas y cazoletas estaba igualmente difundido en otras cortes: En el palacio de Saint Germain en Laye, Jean Héroard, médico del delfín Luis (futuro Luis XIII) testifica el uso de las pastillas que se quemaban en cazuelas con agua de rosas en $1608^{47}$.

Otros preparados olorosos más frescos eran los vinagres. En el recetario se citan varios de estos preparados para refrescar las estancias en días de mucho calor: el «vinagre para regar en el verano» ${ }^{48}$. Podemos imaginar al virrey de Nápoles solicitando a nuestro personaje la pronta elaboración del vinagre de juncia para refrescar sus palaciegas habitaciones durante la canícula napolitana. Apreciaba el virrey la frescura del vinagre porque según afirma Farina en el recetario «no le echava aguas de olor fuerte, sino rosada de mirta y semejantes sin ambar». Muchas recetas requerían del sol para su elaboración, por lo que se deduce que los orígenes de las mismas están en territorios sureños donde el astro rey podía sustituir las alquitaras y demás instrumental; ponemos como ejemplo la receta de «memoria de ambar rosada» que le fue proporcionada al médico por «la duquesa de Palermo» en el año 1638; el éxito de esta receta dependía en gran medida de la intensidad del sol, tal y como aconseja Gavino en el margen: «[...] como todo su primor viene del sol, es precisso que sea mucho y de los mas fuertes del verano» ${ }^{49}$. Es de suponer que durante el ferragosto, Farina, además de producir los acostumbrados vinagres, experimentaría las más arriesgadas recetas de aguas perfumadas.

Aguas, pastillas y pebetes servían al sentido del olfato... pero las virtudes del perfume no se agotaban con la satisfacción de este sentido porque, como demuestra

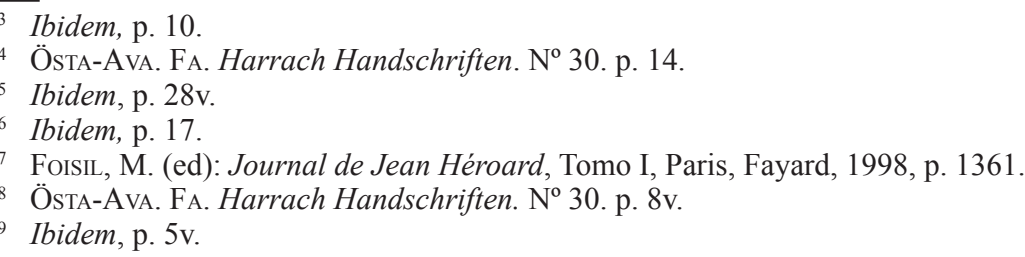


el recetario, los aromas no sólo se olían sino que se veían, se tocaban e incluso se comían o bebían, y es que, cual producto de lujo que denotaba prestigio social, el perfume se adaptó a las formas de representación cortesanas inherentes a las cortes del barroco. En el prontuario de Viena no faltan las aguas perfumadas para beber; el perfume para rociar cueros, lienzos, sábanas o trajes; las bolas aromáticas para llevar y mostrar; los polvos de olor para empolvar guantes; o las alcorzas, dulces que -según el recetario- se elaboraban con los mismos ingredientes que las aguas de olor. El almizcle o el ámbar, combinados con el azúcar propio de todos los dulces aristocráticos, multiplicarían las propiedades medicinales de estos caprichos del arte de la dulcería.

Estamos en disposición de aseverar que el perfume, como arma visual de fineça, fue asiduamente utilizado por la nobleza en el siglo XVII. En aquella cultura de la "representación" debe encuadrarse la aparición de las denominadas bijoux de senteurs, o joyas de perfume, diminutos objetos realizados con piedras preciosas que contenían diferentes combinaciones de esencias en estado líquido o sólido y que el portador aspiraba cuando sentía que debía hacerlo, en principio, por necesidad profiláctica o médica ${ }^{50}$ y más adelante, quizás por gusto y condición. Las complicadas combinaciones de esencias y la distinta percepción que hoy en día se tiene de los perfumes no permitiría adivinar por el olfato si los olores contenidos en estas joyas eran o no del agrado de su poseedor; afortunadamente ciertos testimonios contenidos en recetas hace suponer que el fabricante buscaba un olor que le resultara agradable, a él o al destinatario del perfume.

Entre estas joyas destacan las denominadas pomas ${ }^{51}$, pomander $^{52}$ o Bisamapfel $^{53}$, en alemán, que podían ser de dos tipos: esferas de filigrana huecas que se rellenaban de perfumes de pasta con forma redondeada y pequeñas bolas que imitaban los gajos de una naranja o una granada en cuatro, seis y hasta ocho compartimentos, que se rellenaban con perfumes líquidos y en los que aparecían grabados los nombres de las sustancias encerrados en ellas. Complejidad y distinción hicieron de estos objetos verdaderas joyas. Estas pomas eran portadas en los bolsillos, colgaban de los rosarios o pendían de los anillos de hombres y mujeres de la alta nobleza que, cuando lo deseaban, acercaban el objeto a la nariz para exhalar el perfume. También se usaron frascos diminutos que se colgaban de la cintura y contenían preciadas fragancias. Algunos de estos objetos han sobrevivido a los avatares del tiempo: su belleza, sus diminutas dimensiones, sus preciados materiales: oro y piedras preciosas; su finura y los múltiples detalles de compartimentación, fascinan y demuestran que el continente tenía que reflejar el contenido: los perfumes más exquisitos sólidos o líquidos que,

\footnotetext{
${ }_{50}$ Parece que el origen de las pomas fue profiláctico: Prevenir contagios y pestes. Para combatir la peste se utilizaban máscaras perfumadas, perfumes «violentos de azufre» o «máscaras en forma de cabeza de pájaro cuyo pico estaba lleno de sustancias odoríficas». Véase: Delameau, J.: El miedo en occidente (s.XIV-XVIII) Una ciudad sitiada, Madrid, Taurus, 1989, pp. 180. 161 у 205.

51 Probablemente en el nombre deriva de la palabra pomme, que significa manzana en francés. La palabra alemana Bisamapfel se compone de la palabra Apfel, que significa manzana.

52 Schmitz, R.: «The pomander», Pharmacy in History, 31 (1989), pp. 86-90. La palabra pomander deriba de poma de ámbar.

53 Smollich, R.: Der Bisamapfel in Kunst und Wissenschaft, Stuttgart, Deutscher Apotheker, 1983.
} 
contenidos en esos preciados bijoux de senteurs visibles y tocables, dignos de los más afamados maestros joyeros, se configuraban en una metáfora de la virtuosa apariencia practicada por la nobleza. Perfume y joya simbolizaban la higiene moral, el prestigio social y la alta condición por ello no es de extrañar que sus poseedores quisieran representar sus olores en sus retratos: Existen numerosos ejemplos ${ }^{54}$ como el retrato de Clarissa Strozzi realizado por Tiziano en el que la niña se presenta con una poma que pende de una cadena ajustada a su cintura, o los retratos femeninos de Bartolomé Bruyn en el que las manos de las retratadas sostienen con suavidad rosarios enganchados a bellas pomas de filigrana ${ }^{55}$. Destaca igualmente la poma que cuelga del vestido de Anne Fernely, retratada por Anthonis Mor van Darshorst en $1569^{56}$. En el siglo XVI los burgueses del norte de Europa se hicieron retratar con sus joyas de olor significando así su situación de poder en el concejo de la ciudad de cuya salubridad eran responsables, al respecto cabe destacar el retrato de Jan Gerritz Van Egmond, realizado por Jacob Cornelisz Van Oostsanen en 1518, en el que el burgomaestre sujeta con los dedos índice y pulgar de la mano derecha una poma dorada, unida al dedo corazón a través de una corta cadena enganchada al dedo corazón ${ }^{57}$. La constancia del uso y representación de los más variados y hermosos "continentes" de perfumes, me inclina a otorgar la categoría de tal a la joya en forma de pistola ${ }^{58}$ que pende de la cintura de doña Inés de Zúñiga, obra de Juan Carreño de Miranda fechada en la segunda mitad del siglo XVII; la delicada pistola que luce doña Inés bien podría haber servido para guardar preciadas esencias, ya que es muy similar a le pistolet á parfum que se conserva en el museo Cognac-Jay de la ciudad de París, una pequeña pistola que servía para contener perfumes de finales del siglo XVIII y que es muy similar a la que aparece en el retrato de Carreño. Sabemos que la joya en forma de pistola de doña Inés de Zúñiga no fue una excepción, pues la hermana de la menina María de Sarmiento poseía una muy semejante ${ }^{59}$ y que, adivinamos, utilizaría para los mismos fines aromático-representativos.

Los guantes perfumados, afamados en la corte de Madrid y en el extranjero, alcanzaron un prestigio similar al de las joyas de olor. Los guantes que realeza y personajes de alta alcurnia lucen en sus retratos no podían ser sino "de olor", esencias "visibles" para el ojo barroco que identificaría la virtuosidad del personaje con el cuero perfumado que enfundaba sus manos. Era la época en la que la moda española de cultivar el aprecio de los olores estaba en auge y no había sido todavía superada por la cultura francesa ${ }^{60}$.

54 Wentzel, H.: «Bisamapfel», Reallexikon zur Deutschen Kunstgeschichte, Zentralinstitut für Kunstgeschichte, Stuttgart/Waldsee, 1948, pp. 770-774.

55 Véase: Retrato de una mujer con un rosario. Bartolomé Bruyn, Colonia, Siglo XVI. Museo de Bellas Artes de Lille. Inv., p. 735.

56 Retrato conservado en el Rijsmuseum.

57 Bimbenet-Privat, op, cit, (nota 34) pp. 330-331.

58 Fuster Sabater sostiene que es «una curisoa joya en forma de pistola» Fuster SABATER, M.D.: "Imagen auténtica e imagen modificada: Cuando los cuadros desorientan al expectador", Goya, 303 (2004), p. 368. Aunque no indica que sea de perfume, algo que me atrevo a sugerir.

59 Arbeteta Mira, L.: Grandes maestros del museo Lázaro Galdiano, Catálogo de exposición, Fundación Pedro Barrié de la Maza, La Coruña, octubre 2003-enero 2004, p. 249.

60 CAMPoresi, P.: Il brodo indiano. Edonismo e esotismo nel Settecento, Garzanti, Milano, 1998. 
Los guantes de olor españoles y el perfume en pasta eran preciados regalos diplomáticos que se ofrecían a delegados extranjeros. El cardenal Francesco Barberini recibió varios obsequios de olor en su viaje a Madrid. La vieja condesa de Lemos regaló al cardenal el 4 de agosto «cajitas con diversas pastillas y guantes» ${ }^{61}$. La condesa joven de Lemos le presentó «una pileta de agua santa de ágata y enjoyada, valorada en seiscientos escudos; algunas cajas llenas de cosas de olor, pieles, guantes, pinetti ${ }^{62}$ [pebetes $\left.{ }^{63}\right]$ y pastillas. Rechazó la pileta aceptando el resto» ${ }^{64}$. No menos lujosos fueron los presentes que la duquesa de Terranova le ofreció esa misma tarde: «una cajita de caparazón de tortuga acanalada llena de pinette [pebetes]; dos docenas de pares de guantes de ámbar, dos colchas o cubiertas de ormesí acolchadas, dicen, de olor $\rangle^{65}$

Los guantes perfumados solían ser regalos habituales de los embajadores españoles a las cortes extranjeras: En París, el duque de Pastrana, embajador de España en Francia, ofreció a Luis XIII 24 cueros perfumados y cincuenta pares de guantes. El joven monarca, haciendo gala del odio aprendido a todo lo español, afirmó «ce sera pour en faire des coliers a mes chiens, et des harnois a mes petits chevaux $\rangle^{66}$.

En el recetario de Gavino Farina destacan las siguientes recetas de pomos y polvos para adobar el cordobán de los guantes: «memoria para hacer los pomos de mi señora la princessa de Pacheco» ${ }^{67}$, «memoria para hacer polvos finos para corcovan o cabritos» ${ }^{68}$, «memoria para adovar algun coleto o guantes sin que lleve almizcle ni ambar» ${ }^{69}$, «memoria de polvillos del duque de Montalto» ${ }^{70}$ y cómo no citar la receta de «guantes de almizcle del duque de Montalto» ${ }^{71}$; los azericos, semejantes a los pomos o bolitas de olor también son recurrentes: «memoria de azericos de ambar y Flores» que según Farina olían «muy bien» ${ }^{72}$.

Y del perfume que se ve y se toca, pasaremos al perfume que se ingiere líquido o sólido, como las aguas de beber medicinales. Dos o tres gotas de esta agua en la bebida eran suficientes para obtener resultados ¿medicina preventiva o resolutiva? En el recetario se citan dos aguas «para beber»: «receta del agua de ambar para bever del duque de Nájera» ${ }^{73}$ y la receta «para hacer agua de beber del Condestable

\footnotetext{
${ }_{61}$ Del Pozzo: op. cit, (nota 43), p. 293.

62 La traductora de diario de Cassiano, Ana Minguito, afirma en una nota que no ha podido documentar este objeto que aparece como "pivette"; creo que se trata, sin lugar a dudas, de los pebetes, pastillas de olor que se quemaban y desprendían aromas.

63 Según mi interpretación. Laura Oliván.

64 Del Pozzo: op. cit, (nota 43), p. 294.

${ }_{65}$ Ibidem, p. 295.

${ }_{66}$ Traducción: Servirían para hacer collares a sus perros y arneses para sus caballos. HéroARD, J.: op. cit, (nota 47), tomo I, p. 2044.

67 Östa-Ava. Fa. Harrach Handschriften. N 30 . p. 23

68 Ibidem, p. $23 \mathrm{v}$.

${ }^{69}$ Ibidem, p. 25

$70 \quad$ Ibidem, p. 27.

${ }^{71}$ Ibidem, p. 46.

72 Ibidem, p.16v.

73 Ibidem, p. 6v.
} 
de Castilla ${ }^{74}$, la primera se echaba «en la bebida como cosa de seis gotas y no mas porque e[ra] muy caliente» ${ }^{75}$; para la elaboración de esta agua se utilizaba el azúcar, ingrediente que sabemos, se creía curativo y que igualmente aparece en el perfume que "se come", se mastica y se ingiere como dulce medicinal elaborado con los mismos ingredientes que las aguas olorosas: en el recetario destacan las alcorzas y los bonbanes que, según explica el médico, sólo se diferenciaban de las alcorzas por su forma: eran redondos como una avellana ${ }^{76}$. Los «bonbanes» ${ }^{77}$ de Cobos se hacían con «azucar molida y cernida media onza de Ambar blanco y dos adarmes de Almizcle fino y una clara de huevo fresco» se mezclaba todo hasta obtener un pasta que tras ser amasada se desgajaba para dar forma redonda y pequeña a los «bonbanes». En las alcorzas, el almizcle y el ámbar se combinaban con el azúcar para crear pequeños dulces "medicinales"; en concreto, las alcorzas eran consideradas remedios efectivos contra la melancolía ${ }^{78}$. Muy curiosa es la receta de «alcorzas de barro» almizcladas o con ámbar que, como su mismo nombre indica, se preparaban con barro «del mas oloroso» y muy bien molido, azúcar y almizcle, ingredientes que convertían a la materia prima inicial en un verdadero perfume comible y digerible que no sorprende cuando tenemos constancia de que el barro era consumido por las damas de la corte como remedio eficaz de control de las hemorragias; de hecho, algunas damas extranjeras con estómagos poco acostumbrados a tales usos, murieron a consecuencia de la ingesta de este "ingrediente" ${ }^{\text {"q9 }}$ que, gracias al recetario de Farina, encontramos dentro de los dulces típicos usados por las casas nobiliarias vinculadas a la monarquía hispánica.

Perfumes para ver, comer, beber, tocar y oler. Perfumes para cuatro de los sentidos cinco sentidos (gusto, tacto, olfato y vista) sedujeron al médico del duque de Montalto; sólo el oído parece permanecer ajeno a los beneficios de los aromas... aunque quién sabe si cascabeles, campanillas o sonajeros estuvieron alguna vez perfumados...

74 Ibidem, p. $7 \mathrm{v}$.

75 Ibidem, p. 6.

76 Ibidem, p. 18.

77 Ibidem, p. 18v.

78 De BAEZA, m: Los quatros libros del arte de la confitería, Lib. IV cap. LXXV, Alcalá de Henares, Juan Gracián, 1592, p. 79v. Cit. por MarTínez CReSPO: op cit, (nota 11), p. 71.

79 Carta de Felipe III a su hija Ana de Austria, Madrid, 9 de febrero de 1618: «no ha habido cosa de nuevo mas que haberse muerto hoy Madama Rosa [...] dicen de comer barro», MARTORELL TéLlezGIRón, R.: Cartas de Felipe III a su hija Ana, reina de Francia (1616-1618), Madrid, Imprenta Helénica, 1929, p. 39. 


\section{INFORMADORES, PRODUCTORES Y USUARIOS DE LOS PERFUMES: HOMBRES, MUJERES, NOBLES O PLEBEYOS VINCULADOS A LA CASA DE MONTALTO}

«Visite otra vez al Cardenal de Moncada, y quedaron mis vestidos perfumados de sus olores, tres dias enteros. Non bene semper olet qui semper bene olet ${ }^{80}$

El 19 de septiembre de 1669, el conde de Pötting, embajador del Imperio en Madrid, anotaba en su diario este curioso juicio del cardenal Moncada, Luigi Guglielmo de Moncada y Aragón, VII duque de Montalto, ex-mayordomo mayor de doña Mariana de Austria y como sabemos, magnate de Gavino Farina, el médico que en aquel año de 1669 debía seguir bajo la tutela del "perfumado" cardenal. El perspicaz embajador, con la sutil ironía que caracterizan sus apreciaciones, quiso expresar con aquella sentencia -en la que el "buen" olor se yergue como protagonista- la desconfianza que le transmitía el duque de Montalto. Sentenciando que no siempre "olía bien" el que "bien olía" (subrayado en el original), el conde de Pötting, rompe con la que debía ser una lógica asociación entre el perfume y la nobilitas en el más alto sentido moral. Así, el aparente buen olor, identificado en la cultura nobiliaria del momento con un código ético propio de la alta alcurnia, que desprendía Moncada, se convertía en palabras de Pötting en una máscara, en un engaño de los sentidos y en una advertencia que le inclinaba a mostrarse precavido ante los "buenos olores", que aspiraban a representar la alta dignidad de la nobleza cortesana.

Huelga decir que los olores que impregnaban el atuendo de Moncada fueron realizados por Gavino Farina utilizando algunas recetas del manuscrito de Viena. La breve frase de Pötting tiene un valor incalculable para nuestro estudio porque, al margen de las implicaciones políticas que encierra ${ }^{81}$, revela el "uso" y "disfrute" de los perfumes por parte el duque de Montalto que, por las anotaciones del recetario, sabemos opinaba sobre las recetas: «a mi amo no le gustó ni a mi tampoco» ${ }^{82}$ o «mi amo gustava desta agua sin ambar y almizcle» ${ }^{83}$; o tenía sus preferidas, como «el agua de palas» que sabía hacer su esposa doña Catalina: «el mayor regalo que tenía el duque», escribe Farina; y conservaba algunas de ellas, las guardaba y recopilaba: «esta nota estaba entre los papeles del duque de Alcalá mi suegro», anotación realizada por el propio Moncada y que podría sugerir la puesta en práctica de estas recetas por él mismo.

80 Nieto Nuño, M. (ed): Diario del conde de Pötting. Tomo II, Biblioteca diplomática, Madrid, 1993, 19 de agosto de 1669, p. 62. Subrayado en el original.

${ }^{81}$ El duque de Montalto-cardenal Moncada estuvo vinculado en las conspiraciones de 1668 para derrocar al padre Nithard. Véanse: PILO, R.: "Casi todos los hombres del cardenal Moncada. La conjura de otoño (octubre de 1668-marzo de 1669)", en Bernardo ArEs, J. M. (coord): La Sucesión de la Monarquía Hispánica (1665-1725). La Lucha política en las Cortes y fragilidad económica-fiscal en los Reinos, Universidad de Córdoba, Córdoba, 2006, pp. 255-275. PiLO, R.: Juan Everardo Nithard y sus “causas no causas". Razones y pretextos para el fin de un valimiento, Madrid, Sílex, 2010.

82 Östa-Ava. Fa. Harrach Handschriften. № 30. p.2.

83 Ibidem, p. 3v. 
El hecho de que el recetario de Viena perteneciera a un hombre y además médico de una linajuda casa italiana, ya marca un hito fundamental en la historia de los prontuarios domésticos. Esta certeza podría constituir el único motivo para darlo a conocer, pero el recetario aporta mucha más información a través de las anotaciones de los márgenes, el título de las recetas o el registro de las personas que "dieron" las recetas. En primer lugar, como sabemos, las notas personales de Farina nos descubren que el dueño del recetario puso en práctica todas las recetas infinitas veces ya que se atreve a sugerir variaciones, a mostrar su gusto o disgusto por los olores, a cambiar ingredientes y opinar sobre mayor o menor benignidad de las propiedades prometidas por los informantes; y en segundo lugar, aportan pistas, no sólo de la red de social del médico que relata Pilo en el último apartado, sino también de las personas informantes de las recetas (no sólo mujeres nobles, sino también hombres, algunos plebeyos) y de su relación con las mismas: si las elaboraban o sólo las coleccionaban para que otros las realizaran, si las "hacían" o simplemente pertenecían a la cultura "de" su Casa. La información brindada por el recetario de Farina permite un planteamiento más serio sobre las preguntas candentes que suscita este tipo de documentación ¿Quién "hacía" o practicaba las recetas? ¿Cuáles eran sus usos y sus fines? ¿Quién las usaba? Parece claro que el perfume se presenta como de uso exclusivo de la nobleza, en cuanto a la elaboración, sería necesario averiguar si los nobles, hombres o mujeres, llegaron a elaborar estas recetas con sus propias manos, bien para su disfrute personal, bien para aumentar su prestigio social en una posible competencia "aromática" con otras Casas nobiliarias, o bien con el fin de "regalar" su tiempo ${ }^{84}$, días y horas empleados en la obtención del producto final: un perfume que presumiblemente expresaría su idiosincrasia nobiliaria a los clientes o afectos obsequiados. Otra relevante cuestión ya pergeñada es el origen social y el género de las personas citadas en el recetario y que tienen una importante vinculación con cada una de las recetas.

Para poder responder a todos estos interrogantes, hemos analizado las expresiones utilizadas por Farina en la asociación de nombres y recetas: «diome», «de», «que hacen», «hacía o hacían» y «que se hace en casa de»; así como los géneros y las titulaciones otorgadas a cada uno de los personajes.

Sabemos que cuarenta personas le «dieron» o «enviaron» recetas, de éstas 24 eran mujeres de la alta nobleza: la duquesa de Alcalá, duquesa de Terranova, la duquesa de Nájera, la marquesa de Castelrodrigo, la duquesa de Montalto (Catalina Moncada), la baronesa de La Laguna, la condesa de Chinchón, la duquesa de Osuna, las carmelitas descalzas de Madrid; o de origen noble: doña María de Agramonte, doña Isabel Valenzuela, doña María del Pulgar; mientras que 16 eran hombres: de la alta nobleza: el duque de Montalto «dimoe esta receta el mismo», el duque de Alcalá, el obispo de Valencia, de la nobleza o origen noble: Don Vicente Pimentel, o sin titulo Antonio Cobos, Antonio de Casanueva (ambos guanteros), Francisco Andrés o Andreu, un capuchino: Fray Félix de Albayda. Así, atendiendo a la expresión «diome», un $40 \%$ de las recetas le fueron suministradas por hombres y un $60 \%$ por mujeres.

${ }^{84}$ La expresión "regalar el tiempo" me la regaló, valga la redundancia, el profesor Fernando Bouza en una de nuestras conversaciones sobre recetarios. 
Evidentemente el hecho de que le dieran las recetas no implica necesariamente que estos personajes las practicaran, aunque sí que las conocían bien.

Más seguro es el verbo «hacer» pero no en todas sus conjugaciones. Hemos atendido a las personas que «hacían»o «hacen» recetas y no a las aguas o perfumes que «se hacen en Casa de», veamos el resultado: de once recetas que Farina dice «hacen» o «hacían» determinadas personas o grupos de personas, dos corresponden a hombres: «que hacen los frailes de San Felipe Neri", «que hace don Juseppe Ronolles y nueve a mujeres: «agua de ángeles como la hace la condesa de Puñoenrostro», «pastillas que hace la serenísima doña Ana Margarita de Austria en el convento de la encarnación» «agua de palas que hacía la duquesa de Montalto Doña Catalina a la reina». En total, un $22 \%$ parece que son hechas por hombres y un $77 \%$ por cien por mujeres; aún y todo deben tomarse estos porcentajes con mucha prudencia ya que cuando se dice que una receta la «hace o hacía» tal o cual persona, podría significar que la ordena hacer a criados u otros personajes a su servicio. Quizás sólo podrían tomarse como totalmente válidas el agua que doña Catalina «hacía» a la reina o las pastillas que «hacía» la marquesa de Villanueva del río, y aún así debe tomarse con muchas precauciones.

Por otro lado están las recetas que en su título denotan la pertenencia a una persona: «el agua de beber del condestable de Castilla», «los pomos de mi señora la princesa de Pacheco» o las «pastillas del duque de Uceda». Farina cita muchas recetas «de» Catalina de Moncada «su señora». Todas ellas indican su uso por parte de estos personajes pero no su puesta en práctica personal, aunque tampoco la descartan ya que algunas de estas recetas fueron dadas al médico por los mismos personajes que dan título a la fórmula; sin duda, la partícula «de» implica una relación más estrecha entre personaje y receta que la expresión «usaba», que aparece en el título de unas alcorzas: «las alcorzas que usaba Carlos V», que desecha cualquier elaboración de aquellos dulces por el emperador, al expresar sólo su disfrute. De estas recetas "de" tal o cual persona un $46 \%$ son de hombres y un $53 \%$ de mujeres.

Quedan las recetas que «se hacen en casa de» o «de la casa de», casi todas ellas de la casa del duque de Montalto. ¿Las hacía el mismo duque, alguna de sus mujeres, o ayudantes de Farina además del mismo médico, cuya puesta en práctica de las recetas es indiscutible? Una anotación algo ambigua nos permite sospechar alguna implicación directa del duque en la experimentación de las recetas: Farina escribe en la página dos del recetario: «pero como mi amo queria que las aguas fuesen fuertes ponia à destilar menjui en agua rosada»; entre las dos frases no hay signos de puntuación, algo común en la documentación de la época ¿Era el propio Farina el que se ponía a destilar el menjuí o era el duque de Montalto? Difícil saberlo. Otra anotación parece dar datos más firmes sobre la práctica del duque «mi amo gustava de aquella frescura del vinagre y no le echava aguas de olor fuerte sino rosada de murta y semejantes sin ambar $\rangle^{85}$, también en este caso la expresión podría llevar a equívoco ¿echaba las aguas de suave olor el duque o Farina? Si el duque de Montalto no elaboró o participó en la elaboración de las recetas, sí parece que las supervisó o vio hacer. Nuevas

${ }^{85}$ Östa-Ava. Fa. Harrach Handschriften. $\mathrm{N}^{\circ}$ 30. p. 9. 
investigaciones arrojarán luz sobre estas aguas y pastillas perfumadas que podemos certificar, hacía y experimentaba con notable interés científico y cortesano, el médico hipocrático Gavino Farina.

\section{GAVINO FARINA, LA CASA DE MONTALTO Y LA CORTE DE MARIANA DE AUSTRIA: RECONSTRUCCIÓN DE LA RED CLIENTELAR DEL PRACTICANTE Y COMPILADO}

Por fin ha llegado el momento de presentar la biografía de Gavino Farina. Registrar las fuentes de las recetas nos ofrece un dibujo bastante claro de las frecuentaciones del médico y de los miembros de la élite que le promocionó en la corte de Felipe IV. Nacido en Sacer (actual Sassari, el cabo norte de la isla de Cerdeña) al principio del siglo XVII, Gavino Farina había estudiado gramática y humanae litterae en su ciudad natal. Unos años más tarde decidió trasladarse a Pisa para dedicarse a la filosofía ${ }^{86}$. En la ciudad toscana conoció al médico portugués Gabriel Fonseca de quien fue discípulo y al que siguió a Roma en la época en la que éste fue nombrado médico de Inocencio $\mathrm{X}^{87}$.

Por las noticias que nos ofrece el recetario, sabemos que Farina se encuentra en Roma en los años treinta del siglo XVII y que frecuenta la corte del embajador español cerca de la Santa Sede Manuel de Moura y Corte Real, II marqués de Castel Rodrigo, y marido de doña Leonor de Melo, quien dio y envió al médico algunas de sus más preciadas recetas. Doña Leonor, por su origen portugués, debía conocer bien las bondades de los polvillos de Portugal: su calidad, perfume y textura debían tener fama, así como los elaboradores de perfumes de origen portugués ${ }^{88}$.

El palacio del embajador marqués de Castel Rodrigo era por aquellos tiempos un lugar muy concurrido por altas personalidades políticas: el duque de Alcalá, Fernando Enríquez de Ribera, y su yerno Luigi Guglielmo de Moncada, nuestro VII duque de Montalto solían visitar al embajador español de la Santa Sede con sus esposas: Don Luigi Guglielmo de Moncada se había casado en 1629 con doña María Afán de Ribera, a partir de entonces duquesa de Montalto ${ }^{89}$. Probablemente, en una de aquellas visitas de cortesía coincidieron por primera vez el médico Gavino Farina y el duque de Montalto. Farina, por aquel entonces, estudiaba para la obtención del doc-

86 TOLA, P: Dizionario biografico degli uomini illustri di Sardegna, A. Forni, Bologna- Torino, 1837-38, vol. II, p. 88.

${ }^{87}$ Sobre Gabriel Fonseca, lector de lógica en Pisa de 1609 hasta 1611 cfr. Storia dell'università di Pisa 1343-1737, vol. II, Pisa, Pacini, 1993, pp. 519 y 564. FABroni, A: Historia academiae pisanae, vol. II, Pisa, Forni, 1791, pp. 288-289 hay noticias sobre el nombramiento de Fonseca como médico de Felipe IV.

${ }_{88}$ En la sección de Inquisición del Archivo Histórico Nacional hay un proceso a un pastillero portugués por robo, por lo que es probable que los lusitanos tuvieran fama de perfumistas. Francisco Fernández Francoso, pastillero portugués, causa contra. 1636. AHN, Inquisición 79, exp. 13. En susodicho vendía sus pastillas en Ávila.

89 Pilo, R.: "Moncada-Aragón y La Cerda Luís Guglielmo", DBE, en prensa (nota 2). 
torado ${ }^{90}$ en un clima marcadamente contrarreformista que determinaría su actitud de sustancial fidelidad - que mantuvo durante toda su vida- a las teorías tradicionales ${ }^{91}$. A pesar de que el enfoque hipocrático hubiera sido ya largamente debatido en el curso de la Edad Media, y fuese considerado, en algunos sentidos, anticuado, el médico sardo decidió adoptar el método científico del ilustre griego como fundamento para sus investigaciones sobre la malaria ${ }^{92}$. En la ciudad de los Papas, Farina consiguió una receta de un médico del rey de Francia ${ }^{93}$, lo que indica que en la corte francesa de Ana de Austria y Luis XIV, los especialistas en medicina practicaban la perfumería ${ }^{94}$.

En 1635, Luigi Guglielmo de Moncada fue nombrado virrey de Sicilia. Por aquel entonces, Farina, ya estaba integrado en el séquito de la familia Moncada, por lo que siguió a su señor hasta la isla. Los duques de Montalto se quedaron allí hasta $1639^{95}$. En Sicilia, Farina aprendió y recogió muchas recetas en las que aparecen como ingredientes principales productos típicos isleños: la primera «agua admisclada» del recetario se la dio precisamente el duque de Alcalá Fernando Enríquez de Ribera en Palermo en $1635^{96}$. Siguiendo con las recetas sicilianas, la del agua de clavos de Terranova se la proporcionó la duquesa de aquellos feudos, Giovanna Tagliavia Aragona Cortez, en enero de 1641, cuando los dos coincidieron en Cartanaxeta, dominio mayor de la familia Moncada. El «agua de boltiga» y «el agua de ambar rosada» se las dio la propia duquesa de Alcalá - la hermana del marqués de Castel Rodrigo, Beatrice de Moura y Corte Real - en Palermo en 1634 y en 1638 respectivamente ${ }^{97}$.

El médico sardo regresó a Roma en el año 1638, donde recopiló otras recetas de la marquesa de Castel Rodrigo, Anna Maria Moncada ${ }^{98}$. Sin embargo, a partir de

90 Contini CAPpai, A.: "Discorso su Gavino Farina”, Il Farina, fasc.I, a. II, 1876, p. 6.

91 Sobre la sombra contrarreformista que congeló la vivacidad de la Italia renacentista véase CAstiglioni, A.: Storia della medicina, Mondadori, Verona, 1948, vol. I: Dalle origini alla fine del Seicento, pp. 447-449. En la Roma de Clemente IX fue instituido, gracias al médico papal Giovanni Gugliemo Riva, un museo anatómico, véase RISSE, G.B: "La sintesi fra anatomia e clinica, en Storia del pensiero medico occidentale", en GrmeK, M. D. (coord): Dal rinascimento all'inizio dell'Ottocento, Roma-Bari, 1996, vol. II, pp. 291-334, especialmente las pp. 296-297.

92 FARINA, G: Medicinale patrocinium ad tyrones Sardiniae medicos, in quo natura febris Sardiniae, causae, signa, prognostica, et medendi methodus describitur, Venezia, 1651. Sobre la difusión y la poco cuidadosa interpretación del corpus hipocrático entre la Edad Media y la Moderna, véase GoUREvitch, D: La medicina ippocratica e l'opera Delle arie, acque, luoghi: "Breve storia della nascita e del potere di un inganno scientifico", en Medicina nei secoli. Arte e scienza, 7 (1995), pp. 425-433.

93 Bouza: op, cit., (nota 1), p. 40.

94 Pérez, S. (ed): Journal de santé de Louis XIV écrit par Vallot, Daquin et Fagon, Jérôme Millon, Grenoble, 2004, p. 436. Dentro de los remedios, cita un perfume para el rey de 1653.

${ }_{95}$ PILo, R: Luigi Guglielmo Moncada e il governo della Sicilia (1635-1639), Caltanissetta-Roma, Sciascia, 2008.

96 ÖSTA-AVA. FA. $\mathrm{N}^{\circ}$ 30. p. 1. Puede ser que aquí Farina se equivoque con las fechas porque el duque de Alcalá no se encontraba en Sicilia en 1635, o quizás la persona que copió el recetario se equivocó en la fecha.

97 Ibidem, p. 5.

98 La hermana del duque de Montalto se había casado con Francisco de Moura y Corte Real, hijo del embajador español en la Santa Sede. Pito, R: "Da Palermo alle Fiandre: la marchesa di Castel Rodrigo", MAFrici, M. (coord): Le donne e il potere a Napoli dagli Aragonesi agli Spagnoli, 2010, en prensa. 
1641 lo encontramos en Cartanaxeta con la familia Moncada o, mejor dicho, con lo que de aquella quedaba: la duquesa de Montalto, doña María Enríquez de Ribera, había muerto en Gaeta en 1639, ese mismo año, su viudo había conseguido en Roma concertar la boda de su hermana María Ana con Francisco de Moura y Corte Real. En 1641 Luigi Guglielmo de Moncada decide embarcarse a España donde en 1643 volvería a casarse, esta vez con Catalina Moncada de Castro, hija del marqués de Aytona ${ }^{99}$ y dama de la reina Isabel de Borbón ${ }^{100}$.

Farina permaneció en Sicilia hasta 1644, fecha en la que inició rumbo hacia Madrid para alcanzar a los duques de Montalto, Luigi Guglielmo y Catalina. El médico sardo se ganó la confianza de la nueva duquesa que le reveló nuevos secretos aromáticos, entre ellas la que se convertiría en el agua preferida del duque de Montalto, la muchas veces citada «agua de Palas que doña Catalina hacía a la reina», por aquel entonces Isabel de Borbón. En Madrid, la duquesa de Nájera ${ }^{101}$ participó igualmente en la recopilación del médico con la receta de «polvos de perfumar la ropa de cama del invierno» ${ }^{102}$.

El matrimonio de los duques de Montalto era un apasionado de los olores: Magalotti aseveró que Luigi Guglielmo era uno de los grandes expertos de Europa ${ }^{103}$; por su parte, la duquesa Catalina conocía un importante elenco de recetas adecuadas para los paladares y olfatos reales ${ }^{104}$.

En el prontuario de Farina no faltan las recetas suministradas por la madre y la suegra de Luigi Guglielmo de Moncada ${ }^{105}$. Juana de La Cerda y de la Cueva, su madre ${ }^{106}$, entró en 1631, en el monasterio de la carmelitas descalzas de Nápoles, allí profesó con el nombre de Sor Juana de Espíritu Santo, fue probablemente ella la que dio a Farina la receta de «Agua de Angeles que se haçe en convento de las carmelitas descalzas de Nápoles». Así mismo encontramos recetas de la baronesa de la Laguna, Margarita de Castro y Alagón, madre de doña Catalina Moncada ${ }^{107}$. En

99 PILO, R: "Moncada de Castro, Caterina", en $D B E$, en prensa (nota 2)

100 Para Isabel de Borbón consúltese la biografía: Oliván SAntaliestra, L.: Isabel de Bourbon. (1602-1644), Lisboa, Círculo de lectores de Portugal, en prensa.

101 Podría tratarse de Teresa Antonia Manrique de Mendoza o Nicolasa Manrique de Mendoza Velasco.

102 ÖSTA-AVA. FA. Nº30. p. 42.v

103 Magalotti, L: Lettere sopra i buccheri con l'aggiunta di lettere contro l'ateismo, scientifiche e erudite, e di relazioni varie, Firenze, Le Monnier, 1945, p. 310, .cit. en CAMPORESI, P: Il brodo indiano, pp. $47-48$

104 Doña Catalina de Moncada fue una de las damas recomendadas por la infanta María. Con el tiempo llegaría a convertirse en dama favorita de Isabel de Borbón. PILO, R: "Juegos de Cortes en la época barroca: Éxitos y derrotas de los duques de Montalto", en Martínez Millán, J. y Marçal Lourenzo, M. P: Las Relaciones Discretas entre las Monarquias Hispana y Portuguesa: Las Casas de las Reinas (siglos XV-XIX), Vol. II, Polifemo, Madrid, 2008, pp. 1429-1466, en especial: p. 1433.

105 La madre de Catalina Moncada.

106 La madre de don Luigi era hija del VI duque de Medinaceli. Para el parenteco de Luigi Guglielmo Moncada: Pilo, R.: Luigi Guglielmo Moncada e il governo della Sicilia (1635-1639), CaltanissettaRoma, Salvatore Sciascia, 2008, p. 39.

107 Sobre la relación de la familia con la descendencia regia de lo Castro véase: DelLa-LenguegLia, G.D: Ritratti della Prosapia et heroi Moncadi nella Sicilia. Opera Historica-Encomiastica, Valenza, Vincenzo Sacco, 1657, pp. 447-450 
el recetario aparecen las recetas de la duquesa de Bivona, Aloisia de Luna, abuela de Luigi Guglielmo.

Farina entró en la familia de los duques de Montalto y en 1644 se marchó con ellos a Cerdeña, donde el duque había sido nombrado virrey. El médico regresaba así a su tierra de origen y allí siguió siendo el médico de los Moncada hasta el final del virreinato. En el verano de 1649, mientras se encontraba en la ciudad de Términi, Farina salvó al duque de una enfermedad debida a «soperchio uso di femine» ${ }^{108}$, una hazaña médica que aumentó el cariño de Moncada hacia el que consideró su salvador ${ }^{109}$.

En 1652 la familia Moncada, incluido el fiel Farina, se trasladó a Valencia por el nombramiento del duque de Montalto, virrey de aquellas tierras. Allí se quedaron durante seis años en los cuales se ofreció a Farina un «annuo trattenimento» semejante al de una cátedra $^{110}$. Por aquellos años, Valencia era foco importante en el mundo de la medicina. Importantes médicos pululaban por la Universidad, entre ellos Melchor de Villena, muy conocido por su obra: Relación y discurso de la esencia, preservación y curación de las enfermedades pestilentes que hubo en la muy noble y leal ciudad de Valencia en el año de 1647, publicada en 1648 junto a Vicente Gil y Diego Pruñonosa, dos reputados catedráticos de medicina ${ }^{111}$. En esa misma ciudad, bajo la comisión de Melchor de Villena, el apodado «nuevo Hipócrates valenciano» ${ }^{112}$, se había fundado el Colegio de los Santos Reyes, institución dedicada a la práctica de la medicina destinada personajes ilustres, virreyes y magnates valencianos. Quizás bajo el techo de esta noble institución que casi con certeza debió frecuentar el duque de Montalto, Farina conocería a don Melchor.

Médico y mecenas, durante esos años, viajaron con frecuencia a Madrid con notables resultados: Farina recibió el 30 de junio de 1653 el nombramiento de caballero de la orden de Alcántara ${ }^{113}$. El honor concedido a Farina por Felipe IV le otorgó fama y prestigio que sin duda alegraría a la familia de Luigi Guglielmo. En el año 1659, doña Catalina falleció a causa de un cáncer mamario, el médico sardo nada pudo hacer por salvar la vida de su amada señora ${ }^{114}$; fue un duro golpe. Al año siguiente, duque y médico volvieron a Madrid para ampararse en el amplio paraguas de la corte. Farina siguió coleccionando recetas que entonces le dieron la condesa de Chinchón, la duquesa de Osuna ${ }^{115}$, doña

108 Siotto Pintor, G: Storia letteraria di Sardegna, Cagliari, Timon, 1843, vol. II, p. 294.

109 Farina, G: Epistola in qua morbi historia, quo excellent. Dux de Montalto fuit vexatus, describitur, et censura in ejus curatione ab aliquibus facta, Nápoles, 1650.

110 Della Lengueglia, G.A.: La staffetta privata, Genova, Benedetto Guasco, 1656, p. 161.

111 López Piñero, J. M.: Medicina e historia natural en la sociedad española de los siglos XVI y XVII, Valencia, PUV, 2007, p. 279.

112 Ibidem, P. 279.

113 Archivo de la Corona de Aragón (ACA), Consejo de Aragón, Reg. 325, ff. 211v-213, Privilegio di nomina a cavaliere dell'ordine di Alcantara al dottor Gavino Farina, Madrid, 30 giugno 1653, inéd.

114 Ahn, estado, Libro 104, Carta de Caterina Moncada, duquesa de Montalto, para Francisco de Moura, marqués de Castel Rodrigo, Denia, 28 de mayo de 1659. Para el estudio científico del cáncer del la duquesa, véase FArINA, G.: Apologia in curatione excellent, dominae Catherinae Moncatae, ducissae Montisalti, Valentino Regio Palatio, 1658.

115 Podría tratarse de la esposa de Juan Téllez de Girón y Enríquez de Ribera o de Gaspar Téllez de Girón y Sandoval. 
Isabel de Valenzuela ${ }^{116}$, doña María de Pulgar ${ }^{117}$, don Vicente Pimentel, o doña María de Agramonte. En 1661, don Luigi alcanzó el cardenalato convirtiéndose a partir de entonces en el cardenal Moncada, fue nombrado mayordomo mayor de la reina doña Mariana y al parecer participó en la conspiración contra Nithard en 1668; la vinculación de Moncada con los enemigos de la reina no impidió a Farina conseguir el 11 de junio de 1668 el título nobiliario y el señorío de la villa de Monti para sí y para sus descendientes ${ }^{118}$. Tampoco le impidió mantener una estrecha relación con su primer mentor hasta el final de su vida, tal y como se puede comprobar en el testamento de duque, fallecido en mayo de 1672, en el que Farina aparece como uno de los testigos ${ }^{119}$.

Tras la muerte de su protector, Farina regresó a Cerdeña, donde parece permaneció hasta 1675 como prior de la cofradía de Santiago de la ciudad de Sassari, a cuya catedral (o, según algunos, a la cercana iglesia de Santiago ${ }^{120}$ ), donó una estatua de plata de San Gavino y la suma de mil escudos. En el año 1677 encontramos a Farina de nuevo en Madrid como médico de cámara y en el elenco de criados que eligieron seguir a Mariana de Austria en su destierro a Toledo, que duró más de dos años. Farina regresó a Madrid con el séquito de la reina madre en 1679, allí recuperó su alta posición como médico de cámara de Carlos II y miembro ilustre del protomedicato junto a Francisco Henríquez de Villacorta y Lucas Mestre.

Farina defendió con fuerza la visión clásica frente a las "contaminaciones" de las nueva teorías mecánicas y químicas, propugnadas por la espagírica paracelsiana y la iatroquímica que en el curso del siglo XVII habían encontrado acogida en Londres, Amsterdam, París y Viena, no así en los dominios italianos de la monarquía española o en la mismísima corte madrileña ${ }^{121}$, donde las nuevas teorías fueron obstaculizadas por galenistas e hipocráticos.

116 Podría tratarse de doña Isabel de Acuña Valenzuela, casada en Córdoba con Andrés de Valenzuela y Mendoza, familiar del Santo Oficio de la Inquisición.

117 Podría tratarse de María de Singüeza del Pulgar, hija de Juan García del Pulgar y esposa de Alonso Sánchez Vilagos.

118 Amat Di San Filippo, v: Origen del Cavallerato y de la Noblesa de varias Familias del Reyno de Cerdeña, Cagliari, 1975.

119 Archivo de Estado de Palermo, Protonotaro del Regno, processi d'investiture, Busta 1617, Processo 6196-6197: Testamento di Luigi Guglielmo Moncada, 1672, inéd.

120 Tola, M. M y Ponzelettr, A.: Le Chiese intramuros della città di Sassari, Gallizzi, Sassari, 2001, pp. 22 у 45.

${ }_{121}$ La interrupción vivida en la península italiana y en España por la política contrarreformista, determinó que las dos áreas geográficas no se contaminaran por ninguna "revolución médica". Es cierto que los ensayos contenidos en French, R. y Wear, A. (ed): The Medical Revolution of the Seventeenth Century, Cambridge University Press, Cambridge, 1989, están dedicados de manera exclusiva a Inglaterra, Holanda y Francia. Por lo que se refiere al apoyo ofrecido por la iglesia católica para el desarrollo de la investigación anatómica a partir del siglo XV: GRMEK, M.D y BERNABEO, R.: "La macchina del Corpo", en Grmer, m.D (coord.): Storia del pensiero medico occidentale, 2. Dal Rinascimento all'inizio dell'Ottocento, Roma-Bari, Laterza, 1996, pp. 3-50., especialmente, p. 5. Véanse también: Angeleres, B: Real Filosofía, vida de la Salud Temporal, Sabiduría sóphica, testamento filomédico, arcanos filochímicos. Hipocrática, Galenica, lilibetánica. Parte segunda de la parte primera del Regimiento General, prudente, físico y moral, brevedad, verdad, claridad, en cada género de cathólica y physica sabiduría, Madrid, 1692 y Rey Bueno, M.: "La academia espagírica madrileña (1693) de fray Buonaventura Angeleres: historia de un proyecto fracasado", en Panacea, n 2, agosto 2001. 
Ha resultado apasionante sorprender a un médico -que escribía en latín sus tratados sobre la peste ${ }^{122}$ - practicando recetas domésticas de perfumes y alcorzas en los más alambicados aposentos de los duques de Montalto; conversando con sus señoras, las sucesivas esposas del VII duque sobre las mejores fórmulas de aguas olorosas o pastillas perfumadas; recibiendo instrucciones de guanteros y hombres sin condición que sin embargo conocían los arcanos medicinales de aguas cocidas y pomas nobiliarias; o recogiendo las indicaciones de recetas, propiedad de las nobles mujeres de la familia Moncada, que pasaban sus días y sus noches recluidas en monasterios femeninos, aquellos reductos infranqueables del secreto que sólo ciertos personajes de influencia podían traspasar y que parece Farina traspasó, pues escribe en el recetario que el agua de olor que se hace en el monasterio de la Ascensión de Palermo no ha la hecho pero, suscribe: «yo le visto y es buena» ${ }^{123}$.

A principios del siglo XVIII, un tal Johannis Maria Farina nacido en Santa María Maggiore en el año 1685 creó l'eau de Cologne, revolucionando con su "invento" las cortes europeas. ¿Quién sabe si conoció a Gavino Farina, fue familiar suyo o se inspiró en las aguas perfumadas celosamente guardadas por generaciones de nobles y damas de las cortes reales y virreinales de la monarquía hispánica? Sea o no cierta esta arriesgada relación, consideramos, sin lugar a dudas, que el recetario de Gavino Farina abre nuevas vías de investigación en el terreno de los prontuarios domésticos dedicados a la perfumería y confitería. Así, con este introductorio estudio al recetario encontrado en Viena, queremos despertar curiosidades y abrir interrogantes dentro de este fascinante mundo del perfume de las élites nobiliarias, en las que el "buen olor" se presentó como instrumento medicinal y arma de representación, propia y diferenciada, del universo del barroco.

122 Farina, G.: Medicinale Patrocinium, Venecia, Iacobum Sarzina, MDCLI, Esta obra se puede consultar en la BNE, signatura 3/4031 (1).

123 ÖSTA-AVA. FA. Harrach Handchriften. $\mathrm{N}^{\mathrm{O}} 30$. p. $6 \mathrm{v}$. 